offer much to trusts, fundholding groups, and joint purchasing agencies-and, of course, to patients.

LEONE RIDSDALE Senior lecturer

Division of General Practice,

United Medical and Dental Schools of Guy's and St Thomas's Hospitals, London SE1 1 6SP

1 Cockerell D, Hart YM, Sander JWAS, Shorvon SD. The cost of epilepsy in the United Kingdom: an estimation based on the results of two population-based studies. Epilepsy Research 1994;18: $249-60$.
2 Goodridge G, Shorvon SD. Epileptic seizures in a population of 6000. BMf 1983;287:641-4.

3 Duncan JS, Hart YM. Medical services. In: Laidlaw J, Richens A, Chadwick D, eds. A textbook of epilepsy. Edinburgh: Churchill Livingstone, 1993:705-22.

4 Scambler G. Epilepsy. London: Routledge, 1989.

5 British Epilepsy Association. Towards a new understanding. London: BEA, 1990.

6 Freeman GK, Richards SC. Personal continuity and the care of patients with epilepsy in general practice. Br f Gen Pract 1994;44:395-9.

7 Taylor MP, Readman S, Hague B, Boulter V, Hughes L, Howell S. A district epilepsy service with community based specialist liaison nurses and guidelines for shared care. Seizure 1994;3:121-7.

8 Shorvon SD, Dellaportas CI, Goodridge DMG, Bradbury C. The clinical nurse specialist in epilepsy. Chalfont St Peter: National Society for Epilepsy, 1993.

9 Medical Research Council. Antiepileptic Drug Withdrawal Study Group. Randomised study of antiepileptic drug withdrawal in patients in remission. Lancet 1991;337:1175-80.

\title{
Back pain
}

\section{Emphasise early activity and support it with services geared to active management}

Back pain is a source of misery to its sufferers, to doctors (who remember the intractable cases), and to the Treasury, which foots a steadily increasing bill for sickness and invalidity benefits. In 1992, at the request of the Department of Health, the Clinical Standards Advisory Group set up a committee on back pain to see whether better management was possible. Its recommendations have now been published, together with the government's response.'

No evidence exists to show that the prevalence of back pain has risen in recent years, yet in the United Kingdom, as well as in other countries with well developed social security systems, the number of people receiving disability payments has risen steadily. A $10 \%$ rise is forecast yearly if nothing is done. The report therefore recommends that the Department of Health should discuss the impact of benefit regulations on health care and chronic incapacity with the Department of Social Security. So far European back rehabilitation programmes have not been able to match the effectiveness of those in the United States, ${ }^{23}$ and Europe's more generous benefit regulations may play a part in that failure. ${ }^{1}$

The most important of the report's recommendations can be summarised in three parts: a change in attitudes to back pain, by both the public and doctors; a redeployment of resources for physical treatment; and the development of special services tailored to acute and continuing back pain. The report seeks a "revolution" in the early management of back pain. Once back pain has lasted for six weeks it is increasingly likely to become chronic, and at six months there is only a $50 \%$ chance of return to work. To have any effect on function and employment the measures taken must achieve everything possible by three months. The current arrangements, whereby patients are often referred to a hospital clinic that may have a three month waiting list, must be changed. Moreover, there is no appreciable reduction in the severity of pain and disability after such visits to hospital. ${ }^{4}$

A change in the attitude of doctors is essential. Rather than condoning a slide into disability and dependency, they should see maintaining the person in employment as their priority. For simple backache (when serious disease and root compression have been ruled out) the doctor must reassure the patient that recovery is expected shortly and that active mobilisation is helpful. But to do this the family doctor must have the confidence to do the initial triage, and he or she must be supported by the "acute pain service." Greater availability of physical therapists is needed (which implies that osteopaths and chiropractors are welcome), but family doctors must regain the confidence of seeing the entire episode through, almost always alone. How well patients will accept that back pain is a "common bodily symptom" is uncertain, but sufferers must be told the benefits of exercise rather than rest.
The redeployment of physiotherapists from chronic, unproductive cases to acute ones will not be achieved without agreement on strict protocols. Medical protocols and guidelines have been shown to be effective in reducing time off work in industrial settings. ${ }^{5}$ Some physiotherapists may be redeployed to an acute pain service, but the report suggests that anaesthetists or other specialists from pain services would also be essential in the critical early stages.

For people who still have back pain at six weeks specialist services and a back rehabilitation service are necessary. To prevent inappropriate referrals a consultant led team should provide services focused on the active management of back pain. These consultants will "probably be drawn from orthopaedic surgery, rheumatology, rehabilitation medicine, pain management, orthopaedic or musculoskeletal medicine." This recommendation probably cannot be achieved without the creation of more consultant posts (and specific training for them). The service itself should include physical therapists, psychologists and occupational therapists; there will certainly need to be new posts created for psychologists and occupational therapists.

The government has naturally welcomed the finding that the recommendations can be "broadly cost neutral," but it is easy to see these changes getting bogged down in protracted negotiations with purchasing authorities without some initial help. The government stands to gain most: every $1 \%$ reduction in disability saves $£ 38 \mathrm{~m}$ in work lost and $£ 14 \mathrm{~m}$ in disability benefits; yet the report considers a $10 \%$ improvement to be "modest." As the report says, back pain is a prime candidate for key area status in the Health of the Nation. The first step now is for professionals and the public to be educated along the lines of the recommendations. This exemplary and well researched report should be read by all those concerned in managing back pain, but leaflets explaining the active approach to back pain will have more effect on patients. This material must be provided centrally, to help get the message across.

R M ELLIS

Rehabilitation Research Unit

Southampton General Hospital,

Southampton SO16 6YD

Clinical Standards Advisory Group. Back pain. Report of a CSAG committee on back pain. London: HMSO, 1994.

2 Oland G, Tveiten G. A trial of modern rehabilitation for chronic low-back pain and disability: vocational outcome and effect of pain modulation. Spine 1991;16:457-9.

3 Mayer TG, Gatchel RJ, Mayer H, Kishino ND, Keeley J, Mooney V. A prospective two year study of functional restoration in industrial low back injury. An objective assessment procedure. $¥ A M A$ 1987:258:1763-7.

4 Croft $\mathrm{P}$, Joseph S, Cosgrove S, Jordan L, Papageorgiou A, Pope D, et al. Low back pain in the community and in hospitals. A report to the Clinical Standards Advisory Group of the Department of Health. Manchester: Arthritis and Rheumatism Council, Epidemiology Research Unit, 1994.

5 Weisel S, Feffer H, Rothman R. Low back pain: development and five-year project prospective application of a computerised quality-based diagnostic and treatment protocol. $\mathcal{f}$ Spinal Disord 1988;1:50-8. 